\title{
ENTRE LA ABSOLUTA CONSTANCIA \\ Y LA NULA CONCIENCIA. SOBRE EL SIGNIFICADO \\ DE LA FENOMENOLOGÍA DEL NACIMIENTO \\ EN JEAN-LUC MARION Y MICHEL HENRY
}

\author{
BETWEEN THE ABSOLUTE CERTAINTY AND THE LACK \\ OF AWARENESS. ON THE MEANING OF THE PHENOMENOLOGY \\ OF BIRTH IN JEAN-LUC MARION AND MICHEL HENRY
}

Jaime Llorente Cardo

\begin{abstract}
RESUMEN
El fenómeno del nacimiento, habitualmente descuidado por la filosofía tradicional, se ha convertido en una referencia recurrente, si bien secundaria, en el contexto de la fenomenología francesa actual. El propósito del presente estudio es poner de manifiesto la relevancia del acontecimiento del nacimiento desde el punto de vista de su poder para cuestionar la prioridad que el pensamiento occidental ha concedido al "modo de aparecer" propio de los objetos que el horizonte fenomenológico del mundo torna visibles. En este sentido, las propuestas fenomenológicas relativas al nacimiento de Jean-Luc Marion y Michel Henry contribuyen, cada una a su particular manera, a mostrar el evento de la natividad como paradigma de fenómeno dado como puro acontecimiento, al margen de toda objetividad y más allá de la percepción y la memoria.
\end{abstract}

Palabras ClaVE: Marion, Henry, nacimiento, invisible, acontecimiento.

\begin{abstract}
Having been usually neglected by traditional philosophy, the phenomenon of birth has become a recurrent, although minor, reference in the context of current French phenomenology. The aim of the present work is to show the relevance of the event of birth from the point of view of its power to contest the primacy that western thought has always granted to the "way of appearing" that is characteristic of the objects that become visible thanks to the phenomenological horizon of the world. In this respect, Jean-Luc Marion and Michel Henry's phenomenological proposals concerning birth contribute, each in their own way, to show the event of nativity as
\end{abstract}


a paradigm of that kind of phenomenon given as pure event, apart from all type of objectivity and beyond perception and memory.

KEYWORDS: Marion, Henry, birth, invisible, event.

\section{INTRODUCCIÓN: DE LA "VENIDA AL MUNDO"}

\section{A LOS FENÓMENOS SIN MUNDO}

La tradición filosófica occidental no ha dejado de preterir secularmente el fenómeno del nacimiento para centrar su atención en el extremo opuesto del segmento temporal que limita la duración de la existencia humana, es decir, en la muerte. Y ello no en virtud de la asunción de perspectivas como la adoptada por Spinoza al postular que "Un hombre libre en nada piensa menos que en la muerte, y su sabiduría no es una meditación de la muerte, sino de la vida" (Eth. IV, Prop. LXVII), sino simplemente porque no contempla en el evento del nacimiento nada que merezca propiamente ser elucidado o tematizado. Expresado en terminología heideggeriana, el nacimiento se muestra como un acontecimiento selbstverständlich ("comprensible de suyo") y, por tanto, en absoluto "digno de ser pensado” (denkwürdig). Sin embargo, la fenomenología francesa contemporánea sí ha prestado singular atención al fenómeno de la natividad, y lo ha hecho desde una perspectiva que lo convierte en paradigma de un modo sumamente determinado y relevante de fenomenicidad. De hecho, ya en 1950, en Le Volontaire et l'Involontaire, Paul Ricoeur, tras constatar que efectivamente "La evocación del nacimiento no es familiar a los filósofos; la muerte es más patética", se refiere al nacimiento en términos no sólo de "comienzo de mi vida", sino de expresión de dependencia de mi vida con respecto a otras. Yo soy siempre, en efecto, "puesto por otros" y no por mí mismo, dado que constituiría un palmario sinsentido el hecho de decidir "ponerme" o no a mí mismo desde el punto y hora en que tal acto de decisión (o cualquier otro) me presupone ya necesariamente como "puesto". Esta posición implica una existencia dada con absoluta facticidad y cuyo origen se halla inevitablemente transido de libre arbitrariedad y de azarosa contingencia. De ellas se deriva la descarnada descripción del nacimiento ofrecida inicialmente por Ricoeur: "Esta existencia bruta que yo no he querido, otros la han querido. Peor aún: ellos no la han querido exactamente, puesto que sé bien que se ha tomado una responsabilidad que no ha sido medida, puesto que se ejerció en la vecindad de potencias imposibles de calcular: es una monstruosa confabulación de azar, instinto y libertad ajena la que me ha arrojado a esta ribera" (Ricoeur, p. 542). 
No obstante, el punto de vista adoptado por Ricoeur aún se encuentra excesivamente atenido por un lado a la perspectiva biológica y genética acerca del acto del nacimiento, y por otro a las categorías tradicionales de la metafísica que lo conciben como una suerte de "efecto" derivado de causas anteriores y producido ("puesto") por obra de éstas. De manera inversa, las tentativas fenomenológicas elaboradas recientemente por Jean-Luc Marion y Michel Henry suponen, a nuestro juicio, cada una a su particular modo, sendas contribuciones decisivas al hecho de pensar el fenómeno del nacimiento como ilustración paradigmática de un tipo de fenomenalidad puramente "eventual", absolutamente desligada de toda "objetidad" y ajena, en última instancia, a la exterioridad óntica representada por el mundo objetivamente dado. Una fenomenalidad, pues, de lo invisible, de aquello que no aparece propiamente (o al menos no lo hace en términos de "objeto" mundano), pero que se revela mostrándose bajo el modo de "aquello que se da". Este modo de manifestarse determinado por la pura donación que define a la natividad propicia que la fenomenología del nacimiento sea susceptible de mostrar privilegiadamente en qué términos — por decirlo en términos de Henry — la fenomenalidad del mundo aparece como subsidiaria con respecto a otras fenomenalidades posibles: tal vez, ciertamente menos evidentes o visibles, pero acaso más decisivas y originarias. Se trataría, en suma, de tratar de elucidar este hecho paradójico de la inanidad fenomenológica de lo inmediata y meramente visible (de los "objetos" que pueblan el horizonte del mundo) frente a la no menos paradójica pregnancia adquirida por lo eventual e inaparente.

Porque, ¿acaso no es bien sabido que "nacer" significa fundamentalmente, y antes que nada, "venir al mundo"? ¿No da cumplida cuenta de ello ya el lenguaje natural en su registro cotidiano? Esa luz a la que se refiere la expresión "ser dado a luz", ¿no apunta manifiestamente a la luminosidad abierta del mundo en cuyo seno se manifiesta y aparece todo aquello que se da como "fenómeno"? Y, sin embargo, es precisamente esta luminosidad mundana y el modo de fenomenalización al que da lugar lo que resulta cuestionado por la fenomenología del nacimiento tal como la conciben tanto Marion como Henry. Cada uno a su particular modo. Así, desde la perspectiva marioniana, el fenómeno del nacimiento resulta fenomenológicamente interesante en la medida en que apunta a la posibilidad de ampliar el horizonte fenomenológico hallando un "evento radicalmente acontecial" (événement radicalement événementiel), sin rastro alguno de "objetidad" y que incluso desaparecería en el momento en que se intentase contemplarlo en términos de "objeto".

1 De hecho, en su más reciente obra, Reprise du donné, en referencia a esta ampliación de la racionalidad hacia el ámbito no-objetual, Marion escribe: "Tout phénomène doit-il devenir un 
Por su parte, la fenomenología henryana contradice frontalmente la idea habitual según la cual el nacimiento constituye esencialmente una "venida al mundo". De modo absolutamente inverso, el adviento del sujeto a sí mismo es un acto que acaece en el reino puramente inmanente de la vida absoluta ubicado en una dimensión fenomenológica ajena al mundo. Una vida absoluta que, como veremos, al afectarse antes que nada a sí misma, da lugar al nacimiento del ego viviente. Tanto el puro acontecimiento "no-objetual" (Marion) como la "auto-donación" de la vida (Henry) vinculados al acto del nacimiento acontecen, por tanto, de espaldas al mundo objetivo y a su dimensión de donación. Este es el rasgo común a ambas instancias que nos interesará elucidar aquí. Tal vez el sentido oculto de la fenomenología husserliana, vedado incluso a su fundador, no apuntaba sino al despliegue progresivo de una inanidad fenomenológica del mundo objetivo ajena ya a las aporías propias del idealismo tradicional (y acaso también del peculiar idealismo fenomenológico trascendental apuntado por el "último Husserl"). Abordemos, pues, inicialmente los términos en los cuales tal inconsistencia fenomenológica de lo mundano es tematizada en el seno de la fenomenología del nacimiento elaborada por Jean-Luc Marion en el contexto de su fenomenología general del don.

\section{INMEMORIAL ACONTECIMIENTO DEL ORIGEN: LA FENOMENOLOGÍA DE LA DONACIÓN ANTE LAS PARADOJAS DE LA NATIVIDAD}

Contemplado desde la perspectiva de la fenomenología marioniana del don, el "fenómeno" del nacimiento se erige como arquetipo ejemplar de fenómeno "pura y propiamente acontecial" (événementie), a la vez que como "fenómeno que se muestra verdaderamente sobre el modo de aquello que se da" (Marion 2010a, 51). Precisamente por ello, el fenómeno del nacimiento propio se presenta, desde el comienzo, envuelto en un cúmulo de paradojas, no constituyendo la menor de ellas el hecho de que asuma el estatus de "fenómeno" cuando al sujeto que lo protagoniza en primera persona no le es concedido presenciarlo jamás "con sus propios ojos" ni, por tanto, guardar recuerdo alguno de él, por lo que ha de atenerse al relato de testigos oculares ajenos a sí mismo a la hora de representar tal supuesto "fenómeno eventual" o de intentar reconstituirlo. El nacimiento tie-

objet pour apparaitre? Cette autre distinction fondamentale ne divise plus tous les objets entre phénomènes et noumènes, mais tous les phénomènes entre objets et non-objets. En d'autres termes, il faudrait élargir la raison au-delà des limites de l'objectivation: élargir au doublé sens de l'étendre, mais aussi de la libérer"' (Marion 2016, p. 175). 
ne pues, lugar propiamente sin el yo, en ausencia del sujeto que nace y, en cierto modo, con anterioridad a él. A pesar de ello, el nacimiento se da ante el yo en calidad de "fenómeno" con plena legitimidad, puesto que el ego no deja de sostener una referencia intencional hacia él que intenta colmar de remedos intuitivos tanto propios como indirectamente acogidos. Más tarde tendremos ocasión de cuestionar esta supuesta "intencionalidad". Por ahora nos limitaremos a señalar que es aquí donde juegan un rol relevante factores tales como los testimonios ajenos, los documentos de orden "administrativo" o los propios retazos de memoria secundariamente derivados del evento original que se halla en el umbral de la existencia misma del ego que recuerda. Fenómeno, pues, pero fenómeno "privilegiado" y dotado de una singular especificidad, el nacimiento deviene, en cierto modo, punto de fuga hacia el que apunta la totalidad de la vida del individuo. Una vida que, en una parte significativa de sí, no se ocupa, como apunta Marion en De surcroît, sino de "reconstituirlo, atribuirle un sentido y responder a su silenciosa llamada" (Marion 2010a, p. 52).

El paradójico hecho fundacional de que al sujeto le esté vedado el acceso perceptivo (singularmente la visión) a un fenómeno que constituye precisamente su propio origen, pone de relieve que el "fenómeno" del nacimiento revela la esencial "no-mostración" del origen. El comienzo, lo originario, se muestra, así, justamente como "lo que no se muestra". O, si acaso, como aquello cuyo modo particular de manifestación consiste en la suprema paradoja fenomenológica, a saber: en mostrarse a través de la privación misma de toda manifestación, en la propia imposibilidad de aparecer. De esta forma, conforme a la perspectiva marioniana, el origen del sujeto se ve despojado en cierta manera de su carácter originario desde dos posibles prismas hermenéuticos. $\mathrm{O}$ bien considerando que el evento original del nacimiento acaece con radical anterioridad a que el yo pueda asistir a él (presenciar su propio inicio) y acogerlo como propio, o bien desde la interpretación conforme a la cual aquello que para el yo nacido se muestra como originario es realmente, considerado "en sí mismo", algo derivado de un volumen inconmensurable de acontecimientos previos de los cuales la natividad no es sino un producto o "resultado" más o menos tardío. Esta última perspectiva "causal" que contempla al nacimiento en términos de "efecto" puesto por una serie indecidible de agentes externos al sujeto naciente, es precisamente la adoptada por Ricoeur cuando se refiere al "comienzo de la vida" de cada cual como algo "puesto por otros" y apenas querido libre y verdaderamente por éstos. Con todo, el auténtico núcleo de la suprema aporía fenomenológica ligada al nacimiento (mostrarse en ausencia de toda mostración) no radica en la posible no-originariedad original del 
inicio, sino en elucidar de qué modo el oxímoron epistemológico representado por un "fenómeno" que no aparece incide sobre la existencia del sujeto y la determina en mayor medida que cualquiera de los fenómenos que, secundando su propia esencia, sí se muestran de modo inmediatamente accesible. Rasgo que, por lo demás, no hace sino poner de manifiesto el tradicionalmente no ponderado poder de lo invisible e "inaparente"; una potestad que la "metafísica de la presencia" y su característica fijación en la preeminencia ontológica de lo visible, determinado y "substancial" han tendido a soslayar de forma secular.

Así pues, el paradójico fenómeno "inaparente" de la natividad influye sobre el sujeto como si apareciese. $\mathrm{Y}$, de hecho, con mayor pujanza que todos los demás que sí aparecen, dado que no solamente condiciona y configura al ego, sino que lo "pro-duce", esto es, etimológicamente, lo hace "avanzar hacia delante", hacia la apertura luminosa del mundo. En suma - y aquí la expresión resulta particularmente afortunada - lo “da a luz". Pero, ¿cómo le acaece al sujeto el acontecimiento de un origen privado realmente de originariedad, cuando el origen en general no se muestra y este origen no-originario, por tanto, se mantiene como radicalmente no susceptible de ser mostrado en mayor medida aún? La respuesta de Marion a esta cuestión pasa por postular que el nacimiento propio adquiere legítima carta de ciudadanía como fenómeno en la medida en que, desde su carencia de manifestación directamente visible, desde su penuria intuitiva, comparece como un evento jamás dado en presencia, perpetuamente pretérito, pero a la vez paradójicamente nunca superado ni susceptible de ser preterido. Siempre en cierto modo "presente" de modo indirecto y simultáneamente siempre por llegar. Es de este aporético modo como la fenomenalidad del nacimiento se define, según Marion, como pura événementialité ("acontecialidad") que torna posible lo inicialmente imposible: "Ma naissance se phénoménalise bien, mais à titre d'événement pur, imprévisible, irrépétable, excédant toute cause et rendant posible l'impossible (à savoir ma vie toujours nouvelle), surpassant toute attente, toute promesse et toute prédiction" (Marion 2010a, p. 53).

El fenómeno del nacimiento muestra, pues, un tipo insólito y absolutamente inusual de fenomenalidad que deriva de forma directa de su modo de donación. $\mathrm{Al}$ acontecer con una absoluta penuria de mostración, deviene ejemplo arquetípico de fenómeno que se muestra exclusivamente en el modo en que se da y en la medida en que reviste los atributos propios del don. Su singular excepcionalidad reside en la posibilidad única de llegar a darse sin tener por ello que mostrarse, que aparecer. Su donación no equivale aquí a su aparición efectiva ni la implica necesariamente. Se trata de un fenómeno que cuenta con el privilegio de poder efectuar su donación en cierto modo en la oscuridad, al margen de la luz del mundo en 
cuyo seno aparecen el resto de los fenómenos. La "fenomenología material" de Henry se articulará, como tendremos ocasión de ver, en torno a esta posibilidad de manifestación no luminosa y radicalmente "acósmica".

El carácter preeminente del fenómeno del nacimiento desde el punto de vista fenomenológico descansa sobre su carácter de "acontecimiento" par excellence. Un fenómeno pura y netamente événementiel que, en cuanto tal, se da sin necesidad de aparecer y que, por ello mismo, al fenomenalizarse en ausencia de toda mostración, afecta al sujeto. Esta afección consiste en dar al ego no solamente la ipseidad misma que lo constituye como tal (su soi-même), sino también en darle en cierto modo un yo anterior a él mismo (un moi que precede a todo moi). Un me en ausencia del cual el sujeto no se hallaría aún presente para poder resultar objeto de afección alguna. Además, el nacimiento aparece como un evento privilegiado también merced al modo en el que consuma y ejemplifica la inserción de la subjetividad en el flujo de la événementialité. Gracias a la constante referencia a ésta, el sujeto asume con plenitud la investidura de "adonado" (adonnè), es decir, de instancia que acoge el fenómeno primigenio y originario dando así lugar a la posterior recepción de todos los restantes. Por todo ello, el nacimiento pertenecería con plena legitimidad a la esfera de los llamados por Marion "fenómenos saturados" o también "paradojas". Fenómenos en los cuales el exceso de intuición, de visibilidad, de fenomenalidad, colma, neutralizándolas, las capacidades conceptuales del sujeto y contraviene sus facultades intuitivas, dando lugar al surgimiento de un modo de percepción que no puede ser descrito sino en los paradójicos términos de una "contra-experiencia".

Exceso, pues, de intuición con respecto a la intención que "estalla irremediablemente desde mi nacimiento" a través de una "primera impresión originaria" y cuyo acontecer da lugar con posterioridad a una cadena indecidible, impensable, fortuita y espontáneamente no previsible de impresiones ulteriores: aquellas que jalonan el decurso de una vida humana. El origen del yo, por tanto, le resulta hermético e impenetrable al propio ego no de modo contingente, sino constitutivo, dado que el fenómeno primigenio (el nacimiento como inicio) ya se presenta como una "paradoja" fenomenológica que "satura de intuiciones toda intención" (Marion 2010a, p. 54). Así pues, el inicio, lejos de darse bajo los ropajes de la falta o la carencia, se define por un modo de donación definido por el exceso, por la sobreabundancia de fenomenicidad visible. Una desmesura y demasía que, por lo demás, impregnan inevitablemente el cariz que habrán de revestir todas las donaciones susceptibles de advenir en lo sucesivo; cariz determinado por aquel que podríamos atrevernos a designar como el nuevo "principio de todos los principios": por la ley del aparecer conforme a la cual "nada se muestra si desde el comienzo no se da". 
El nacimiento se define, asimismo, por su radical anterioridad a todo pensamiento desde el momento en que el yo adviene a la existencia tout court y a su propia existencia en particular, en virtud de un modo de darse totalmente ajeno al del ego cogitans. El nacimiento pertenece al sujeto al margen de todo pensamiento y antes de que éste se dé. Antes de existir se requiere, no pensar, sino nacer. Y el acto de nacer acontece de tal modo que el yo adviene a sí mismo él mismo al margen de toda previsión, de toda premeditación y de toda comprensión, puesto que, propiamente hablando, no existe todavía, y, por tanto, en menor medida aún puede darse como elemento "pensante". El yo se halla paradójicamente ausente de aquel acto en virtud del cual deviene presente. Y ello sucede aun cuando el yo pueda elaborar una interpretación fundada retrospectivamente en testimonios ajenos que le permita reconfigurar aquellos momentos del pasado a los cuales no le ha sido dado propiamente asistir, a los que se le ha denegado por principio el acceso perceptivo, es decir, aunque cuente con la posibilidad de representación. Este constructo hermenéutico hilvanado a base de retazos memorísticos de segunda mano se limita, conforme al punto de vista asumido por Marion, a apoyarse en el nudo carácter fáctico del nacer: "en el hecho (la facticidad) de mi nacimiento, en sí mismo además sin causa e imprevisible, para asignarle, demasiado tarde y siempre muy parcialmente, una coherencia y un carácter concebible que se supone deberían evitar el absurdo y hacerlo simplemente verosímil” (Marion 2010b, p.125). De este modo, los relatos y recuerdos indirectos sobre el nacimiento propio aportados por los otros, llegan inevitablemente demasiado tarde al acontecimiento - ya siempre advenido— de la natividad. Se sitúan siempre "delante o, más bien, detrás de lo inmemorial" (Ibid.). ${ }^{2}$

Porque el tiempo del nacimiento es el tiempo de lo inmemorial, ${ }^{3}$ de lo esencialmente sustraído a la rememoración; tiempo en cuyas aguas naufraga toda posible anámnèsis del origen y que, por ello, aún determinando la totalidad de la secuencia posterior de los instantes que constituyen una vida, permanece perpetuamente en la esfera de la inaccesibilidad. ${ }^{4}$ Intuimos aquí uno de los rasgos

${ }^{2}$ Comparecen, según la descripción marioniana, "figés, immobiles, muets soudain, devant le momento obscur, silencieux et inaccesible de la naissance, de la gestation et de la conception -période sans parole, sans conscience, sans memoire” (2010b, p. 125).

3 A ello se refiere Ricoeur cuando escribe: (Ricoeur 2009, pp. 551-553).

4 A este "tiempo anterior al tiempo" se refiere Levinas a la hora de incardinar el momento de la asunción de la responsabilidad ética hacia el prójimo: "Aquí el golpe de la afección hace impacto traumáticamente en un pasado más profundo que todo lo que yo soy capaz de reunir mediante la memoria, mediante la historiografía, todo lo que soy capaz de dominar por el a priori; se trata 
decisivos propios de la subjetividad que el fenómeno del nacimiento contribuye a sacar a la luz: el hecho fenomenológicamente paradójico de que la memoria se despliegue solamente a partir de lo inmemorial, de que la razón surja a instancias de aquello que carece de ella (el nacimiento contraviene directamente el principium "reddendae" rationis leibniziano), de que aquello que constituye al yo tenga lugar en ausencia del yo. De que finalmente la consciencia en vigilia solamente se alce desde la noche de lo inconsciente. En suma, por decirlo con la concisa expresión de Schelling en el Freibeitsschrift de 1809, el hecho de que en el origen del Ser, como en el nuestro propio, "de esta ausencia de entendimiento (Verstandlosen) es de la que nació propiamente el entendimiento" (Schelling 1989, pp. 168-169) y de lo "a-conceptual" surgió paradójicamente el concepto. El nacimiento deviene, contemplado desde este ángulo, presentimiento de la preeminencia ontológica de lo invisible y puramente dado como evento, sobre aquello —aparentemente más perentorio y consistente- que se ofrece de forma directa a la mirada en calidad de "objeto" mundano.

Así pues, si realmente "mi nacimiento no adviene sino como un imposible inmediatamente efectivo" (nueva paradoja), "de entrada factual, sin precaución, ni previsión, ni provisión” (Marion 2010b, p. 125), entonces, al realizarse como imposibilidad, pone en libertad — paradójicamente — una incontable pléyade de posibilidades. Una miríada virtualmente ilimitada de eventualidades posibles no susceptibles de ser predeterminadas ni previstas. Así, cuando la imposibilidad del nacimiento se torna real, configura y fija posibilidades ya no definibles a través de los conceptos del sujeto, del ego nacido, sino puestas en franquía por el nacimiento mismo, propiciando con ello la forja de conceptos conforme a una disposición opuesta a la fijada por la posibilidad tal como ésta ha sido concebida tradicionalmente por el pensar metafísico. Solamente, pues, como indicábamos con anterioridad, nos es concedido el acceso efectivo a la más radical de las posibilidades merced a una paradójica "contra-experiencia": aquella ligada a la paradoja representada por la imposible posibilidad del propio nacimiento.

de un tiempo que es anterior al comienzo" (Levinas 1987, p. 150). Asimismo, en su primera y fundamental obra L'événement et le monde, Claude Romano alude a esta temporalidad inmemorial propia del nacimiento en los siguientes términos: "El nacimiento es en sí mismo abertura a un pasado «más viejo» que cualquier pasado asumible, un pasado que nunca ha sido presente para el viviente. Su finitud reside entonces para él en que, siempre ya arrojado fuera de su origen y no pudiendo nunca coincidir con él, recibe su sentido de una parte distinta que no es la de su aventura y, en esta misma medida, está abandonado a un destino" (Romano 2012, p. 116). 
Cuando se insiste en pensarlo inapropiadamente desde las categorías propias de lo "objetual" y no desde la perspectiva del puro acontecimiento que contraviene esencialmente tales categorías en virtud de la "contra-experiencia", el fenómeno de la natividad cristaliza descriptivamente en un cúmulo de hechos paradójicos. Ya nos hemos referido ocasionalmente a algunas de estas cruciales paradojas durante el curso de nuestra argumentación, pero es en Certitudes negatives (2010) donde Marion expone de modo más taxonómico y sistemático las tres paradojas capitales de la natividad, así como las implicaciones que de ellas se derivan. La primera de ellas nos resulta ya familiar. Alude al hecho de que el propio nacimiento, "el acontecimiento que a nadie concierne más que a mí" y que resulta vedado a cualquier otro, tiene lugar sin mí, en la inconsciencia de mí mismo en tanto que ego, y sin dejar recuerdo alguno tras de sí. Podría decirse que, en cierta manera, aquel(lo) que nace en el instante del nacimiento propio no es aún uno mismo: aquel que es capaz real y propiamente de referirse a sí mediante el término "yo". Es desde esta intuición que Marion desliza la inquietante fórmula según la cual: "Je nais aprés ma naissance et, un temps durant, je nais mort-nê" (2010b, p. 294). Este rasgo resulta llamativo en la medida en que — repárese en ello- cuestiona fenomenológicamente no sólo ya el estatus óntico propio de los objetos y del horizonte marcado por el mundo objetivo en general, sino también la propia consistencia ontológica de la subjetividad. $\mathrm{Al}$ menos durante un período situado en la vecindad de su mismo origen. Marion prefiere, sin embargo, interpretarlo nuevamente como signo que denota la inequívoca presencia de un fenómeno puramente événementiel, libre de "objetidad", permanentemente "pasado": "puesto que es — si es que propiamente 'es' - aquello que permanece por discutir: pasándose, sobrepasándome, pasando siempre ya siendo pasado (étant passê)" (Ibid.).

La segunda paradoja nos es también ya parcialmente conocida. Se refiere al hecho de que el nacimiento resulte imposible de asumir por parte del sujeto que nace, en la medida en que se trata de un evento inmemorial en el que el ego habría de guardar recuerdo de un suceso que jamás ha presenciado en primera persona. ${ }^{5} \mathrm{El}$ inicio del ego muestra así caracterizarse en virtud de una "original inaccesibilidad al origen". De esta forma, además de hallarse absolutamente al margen de la exigencia de fundamento y razón expresada por el principium rationis o Satz von Grund, el nacimiento propio contraviene, al darse en ausencia de "causa", la necesidad de adscribir

${ }^{5}$ En palabras de Romano: "El nacimiento se muestra, en ese sentido, en rigor inmemorial [...]. Configurando por vez primera mis posibles y el mundo, el nacimiento abre mi presente a un pasado más antiguo que cualquier pasado asumible, a un pluscuampasado que nunca ha sido presente" (Romano 2012, p. 119). 
a todo fenómeno su correspondiente principio. Con ello, el ego se muestra como algo carente de principio al cual apelar o retornar, pero también como una instancia incapaz de ponerse a sí misma como principio. Marion se refiere a esta falta de arkbé propia del sujeto nacido mediante el término "a-narquía": inaccesibilidad y ausencia del principio desde la cual el nacimiento socava los cimientos mismos de la identidad del sujeto. La igualdad y perfecta coincidencia del ego consigo mismo asentada por el "principio de identidad" es, pues, disuelta por el carácter "anárquico" que define al acto de nacer, con lo que el yo deja de pertenecerse originariamente a sí mismo. Mejor dicho: el yo se descubre a sí mismo como no habiéndose auto-pertenecido jamás, como algo a lo que únicamente pertenece su "no-pertenencia", su simple estado de facto nunca voluntaria ni libremente elegido, sino siempre adjudicado desde el "exterior". Es en este sentido en el que Marion habla al respecto del nacimiento de una "facticidad absoluta" (derivada precisamente de esa asignación involuntaria en la que él consiste), puesto que no es posible que el nacer se presente como fruto de una decisión o de un acto volitivo. ${ }^{6}$ Repárese nuevamente en que la "paradoja de la anarquía" - junto con la anterior y su contradictorio estado de "muertonacido" - no solamente ocasiona un severo marasmo al dominio ejercido por los tres principios lógico-ontológicos tradicionales (identidad, no-contradicción y razón suficiente), sino que resquebraja seriamente la propia identidad del ego al hendir de modo originario las raíces de las cuales se nutren la autonomía y la firmeza propias de la subjetividad (al menos de aquella asentada por la metafísica moderna). ${ }^{7}$

El rasgo decisivo que permite establecer fenomenológicamente una cesura diferenciadora entre el nacimiento y la muerte es consecuencia de esta peculiar "heteronomía anárquica" derivada de la pura facticidad del nacer. En efecto, siem-

${ }^{6}$ Frente a ello, Romano escribe a propósito de la facticidad propia del nacimiento lo siguiente: "este acontecimiento originario [el nacimiento] que es también el origen de cualquier otro acontecimiento, se muestra en rigor impensable en términos de facticidad. Porque la facticidad, tal como es analizada especialmente por Heidegger, es un momento del ser-en-el-mundo que se opone a la existencialidad [...]. Pero precisamente el nacimiento no puede ser una estructura ontológica del ser-en-el-mundo; de lo que trata, al contrario, es del propio carácter de acontecimiento del mundo" (Romano 2012, pp. 110-111).

7 Un rasgo que, nuevamente, no parece haber escapado a la mirada de Romano: "el acontecimiento [también el de la natividad], en su radical impreparación, se sustrae constitutivamente a cualquier estructura de acogida; de suerte que es el concepto mismo de «subjetividad» el que se muestra insuficiente para aprender su sentido" (Romano 2012, p. 112). Así, "el acontecimiento de nacer me es asignado, me es destinado (en dativo) según la heteronomía de un don [...]. Don que se destina a mí, por consiguiente, antes de cualquier poder de apropiarme de este acontecimiento, es decir, antes de toda propiedad sobre mí mismo y toda ipseidad' (Id. 114). 
pre resulta plausible influir de algún modo a voluntad sobre el advenimiento de la propia muerte, bien mediante una decisión clínica (ser privado de los medios técnicos que mantienen artificialmente la vida, rehusar ser objeto de la terapia o medicación prescritas, etc.), bien mediante el propio acto de auto-supresión voluntariamente decidido y asumido. Cabe igualmente la posibilidad de situarse - de forma igualmente deliberada y consciente- en situaciones que entrañan un elevado volumen de riesgo para la propia vida o acelerar las probabilidades de advenimiento de la muerte a través del mantenimiento de hábitos conscientemente reconocidos como nocivos por parte del sujeto que los lleva reiteradamente a cabo. Es posible, igualmente, decidir sobre la muerte de los otros mediante la práctica del asesinato, la firma de una condena a muerte o la omisión de socorro en situaciones de extremo peligro para la vida ajena. Sin embargo, en el caso del nacimiento, extremo opuesto de la trayectoria vital individual, no se da en absoluto esta posibilidad de incidencia e intervención. ${ }^{8}$ De hecho - como sugería ya Ricoeur-, ni siquiera los progenitores "deciden" de forma totalmente digna de tal nombre dar lugar a aquel nacimiento que otro ser considerará como propio, por mucho que ellos mismos estimen "subjetivamente" lo contrario. Recordemos: "ellos no la han querido exactamente", puesto que tal supuesta decisión "se ejerció en la vecindad de potencias imposibles de calcular".

La vida, su origen al menos, presenta, pues, un gravamen de facticidad mucho más acusado que el susceptible de serle imputado a la propia muerte, a pesar de los tópicos culturales referentes a la "fáctica" inevitabilidad del hecho de morir. He aquí nuevamente otra paradoja puesta de relieve por la fenomenología del nacimiento. En todo caso, el soslayo temático del nacimiento y la atención inversamente dispensada por la filosofía occidental al fenómeno de la muerte a los cuales nos referíamos al comienzo de la investigación, adquieren en este tramo del camino un cariz renovado. Observados a la luz de lo expuesto, el nacimiento surge como un evento inaprehensible para el ego y continúa manteniendo tal estatus a perpetuidad, mientras que, a la inversa, la muerte, en tanto que se presenta, según Marion, como un "origen al revés" (à rebours) o "bajo la figura de un contraorigen” (2010b, p. 295), permite aún al sujeto adueñarse de ella. Se muestra, así,

\footnotetext{
8 A este respecto, resulta pertinente evocar aquí las observaciones fenomenológicas de Jan Patočka según las cuales: "El nacimiento y la muerte son esencialmente discontinuos. En el nacimiento y la muerte no hay posibilidad global que se concretice, que se despliegue en posibilidades parciales. Al contrario: es el presupuesto de toda posibilidad el que es puesto o suprimido" (Patočka 1995, p. 46).
} 
como una posibilidad susceptible de asunción por el ego en la medida en que éste todavía cuenta con un margen para decidir cuándo y cómo actualizarla, esto es, experimentarla de modo efectivo. Ello se pone de manifiesto en el acto del suicidio entendido como postrer acto de aprehensión y apropiación afirmada por el yo en referencia a sí mismo. Puede darse, así, una "auto-muerte”, pero nunca un "autonacimiento"; el nacimiento es radicalmente heterónomo, obedece a leyes distintas a las propias, es siempre "hetero-nacimiento".

Llegamos así a la tercera y más novedosa de las paradojas de la natividad: aquella que nos sitúa ya en la vecindad de la teoría sobre el nacimiento formulada por la "fenomenología de la vida" de Michel Henry. Ciertamente, sólo el viviente puede nacer, pero "nacer" no implica necesariamente "venir al mundo". No coincide con el hecho de darse en la luminosidad del horizonte objetivo que hace aparecer los fenómenos mundanos, es decir, los “objetos". Éstos permanecen esencialmente ajenos al fenómeno del nacimiento, por mucho que refuljan a la luz ontológica del "mundear" (welten) heideggeriano, y además derivan perfectamente de causas que permiten determinar su comienzo y su final. No sucede lo mismo en el caso de los vivientes, cuyo nacimiento, como hemos visto, acaece al margen de toda producción de orden causal. En esta particular situación, el viviente se abre ciertamente a lo peculiar y específico del mundo (su luminosidad en la que aparecen las cosas), pero de modo inverso esta luminosidad fenoménica universal no penetra en lo esencial y constitutivamente propio del viviente: en la vida que hace de él lo que es. ${ }^{9}$ La fosforescencia del mundo únicamente ofrece a la mirada lo estrictamente visible, con lo que la vida en su peculiar modo de donación, en lo que Marion llama "su cómo fenomenal" (esencialmente invisible y "nocturno”, dirá Henry), se le escapa y le resulta siempre inasequible.

Se impone aquí, por tanto, la necesidad —ya apuntada por el último Heidegger — de que la fenomenología se transmute en "fenomenología de lo inaparente", y de que la hermenéutica se oriente hacia la interpretación de aquello cuyo modo de darse y aparecer consiste paradójicamente en no mostrarse a la luz del mundo. La vida es uno de estos "fenómenos" para los que se precisa algo más que la luminosidad mundana a la hora de definir su particular forma de mostrarse, su

\footnotetext{
9 En sentido totalmente inverso, pero desde una perspectiva igualmente fenomenológica, escribe Patočka en El mundo natural como problema filosófico: "Somos aceptados por aquello en lo cual nacemos; aceptados por el mundo en el cual estamos por el hecho de nuestro nacimiento. Es del mundo que nosotros nacemos; naciendo, nos separamos de la conexión de sus procesos, devenimos algo para sî” (Patočka 2016, p. 230).
} 
dimensión fenoménica, a saber: lo invisible (el reconocimiento intersubjetivo, la conexión lingüística, la libertad individual o la silenciosa apelación ética emanada del rostro ajeno). Tal necesidad conduce a la cuestión relativa a los términos en los que cabe plantear la posibilidad y los límites de una fenomenología de la vida en general. Henry insistirá, como veremos seguidamente, en la idea de "autodonación" de la vida en su inmediación patética y acósmica como esencia de la invisibilidad esencial propia de lo vital, como ese "algo más" (ese plus o surplus) que excede la fenomenicidad del mundo objetivo.

Marion, por su parte, extiende esta invisibilidad vuelta de espaldas al horizonte mundano tanto al nacimiento del viviente como a la propia vida de la cual éste constituye el inicio. En efecto, dado que el nacimiento ubica al viviente, como se acaba de apuntar, en una dimensión del aparecer inalcanzable para la luz del mundo, de ello se sigue que tanto el nacimiento mismo como la vida del viviente que comienza con él resultan, estrictamente hablando, "fenómenos invisibles". Un oxímoron que cobra sentido desde el instante en que, desde la perspectiva de la "fenomenología de lo inaparente", se constata que el nacimiento "se muestra" como invisible no sólo para el sujeto naciente que no asiste propiamente a él, sino también ahora para aquellos espectadores del mismo que podrían inicialmente atestiguarlo de primera mano. Tales testigos que supuestamente presencian in the flesh el acontecimiento del nacer, se limitan en verdad únicamente a percibir de forma sensible el evento mecánico mediante el cual un organismo con unas determinadas características es producido por un organismo anterior ya existente. Pero esto no significa en absoluto que ellos capten el fenómeno de la vida en o través de ese organismo maquinal, puesto que la vida permanece en él inaparente, invisible, oculta a la luz del mundo a la que el organismo es "dado a luz". Esta invisibilidad inmediata y originaria del nacimiento se prolongará durante toda la vida del viviente acompañándolo a perpetuidad; tan hurtada a la mirada como lo es esencialmente esa propia vida. Únicamente a través de mediaciones interpuestas de orden comunicativo o intersubjetivo (el "algo más" excedente al aparecer del mundo al que nos referíamos anteriormente) resulta ocasional, efímera y parcialmente posible que la vida se dé a ver, si bien de forma no-inmediata.

El nacimiento propio es, pues, un fenómeno que "se da" sin tener, no obstante, que mostrarse. Una donación carente de manifestación que, paradójicamente, no por ello pierde su condición de "fenómeno". Muy a la inversa, de hecho, abre la vía a través de la cual pueden ingresar en el horizonte fenomenológico tipos de fenomenicidad diferentes a los habitualmente considerados. El nacimiento da cumplida fe del acontecimiento original e invisible del don, de la donación que 
siempre antecede a la mostración efectivamente visible de los fenómenos, al ser capaz de elevarse a través de lo aún no visto. En este sentido, apunta Marion, "el nacimiento constituye el archi-fenómeno, aquel que instituye la anarquía de todo fenómeno apareciendo como un acontecimiento" (2010b, p. 298). Y es que, efectivamente, el nacimiento concita en sí la totalidad de los atributos o rasgos distintivos propios del "acontecimiento" en sentido eminente. Es más: el evento original del nacimiento implementa la "acontecialidad" misma en virtud de la cual se despliega todo fenómeno en la medida en que es un acontecimiento que, como tal, sucede y pasa (esto es "acontece”). Así pues, más que como événement tout court, como événement par excellence o incluso como premier événement, el nacimiento ha de ser contemplado en términos de don reducido a la pura y simple donación: como don absolutamente événementiel. Una donación invisible que, sin embargo, ejercen todos los fenómenos cuando, apuntando al referente marcado por el fenómeno original de la natividad, han de "darse" con carácter forzosamente previo a poder "mostrarse".

Prueba de este carácter "acontecial" constitutivamente suyo, es que el nacimiento carece propiamente tanto de donador como de donatario. Nadie "da" propiamente el nacimiento, puesto que los progenitores no se hallan en disposición de asumir tal papel stricto sensu (ausencia de donateur), pero tampoco nadie lo "recibe" en sentido propio, dado que su único posible receptor no sólo permanece ajeno al evento del nacer cuando éste tiene efectivamente lugar, sino que permanece en lo sucesivo en un estado de retardo con respecto a él. Por si no bastase con ello, un indicio inequívoco, además, de la événementialité del nacimiento lo constituye el hecho de que aquello que es dado como don en su acto de donación nunca se presenta como "objeto", como "ente" —en cuanto tal determinado y consistente-, ya que lo así dado no es sino la vida, y ésta puede asumir cualquier estatuto ontológico posible excepto el de la "objetidad". La vida no es propiamente ni siquiera un "algo", un Et-was, some-thing o quelque chose, puesto que no es, con toda certeza, una "cosa" e incluso, al decir de Marion, "puede incluso dudarse simplemente de que sea. Nada es dado: la vida no es nada, no es" (Ibid.).

¿En qué reside, pues, la singular relevancia del fenómeno del nacimiento desde la perspectiva de la fenomenología marioniana de la donación? Fundamentalmente en el hecho de aportar una conspicua ejemplificación de fenómeno puramente événementiel, es decir, nulamente perceptible e interpretable en términos de "objeto" y que no sólo se muestra absolutamente refractario al modo de fenomenalización propio de éste, sino que únicamente cobra entidad y sentido fuera de él. Así resulta constitutivo del nacimiento en cuanto fenómeno el acaecer en el interior de una 
fenomenalidad "acontecial", "no-objetual", y, a su vez, esta "no-objetualidad" se muestra como aquella propia de la vida invisible que "no es" y en cuya donación "nada se da" propiamente. Partimos, pues, del examen del nacimiento como puro evento sin rastro de "objetidad" en el contexto de una "fenomenología del don", para arribar finalmente a una "fenomenología de la vida" invisible. Ambas tienen en común nuestro inicial hilo conductor que no estará de más evocar aquí nuevamente: el hecho de situarse más allá o más acá de la fenomenalidad propia del mundo y de los fenómenos objetivos concretos que la habitan. Momento es ya, pues, de explorar el modo en el que la "fenomenología de la vida" propuesta por Michel Henry concibe el fenómeno del nacimiento como un evento no intramundano, dado con independencia de la luminosidad propia de la "verdad del mundo".

\section{MiCHEL HENRY O EL ADVENIMIENTO A LA VIDA SIN MUNDO}

Ya desde su primera obra, L'essence de la manifestation, Henry concibe la esencia de la vida como un "abrazo patético" que se auto-afecta inmediatamente y cuya donación a sí mismo acontece siempre de espaldas al mundo, de forma "acósmica”. La verdadera vida, podríamos decir con Rimbaud, "está ausente”, replegada en la invisible dimensión de la pura inmanencia vital. Fenomenológicamente hablando es rigurosamente cierto que, como añade el poeta francés, "no estamos en el mundo": "Porque la esencia de la realidad y de la vida reside y se realiza en lo invisible, no se puede, en efecto, hallarla en el mundo: nada de lo que se exbibe en éste puede contenerla ni hacerla manifiesta" (Henry 2015, p. 431). Henry aborda desde esta perspectiva los rasgos propios de una posible fenomenología del nacimiento. Conforme a éstos, en principio "nacer" significa "ad-venir al ser", "llegar a la existencia, "venir al mundo", del mismo modo en que "morir" quiere decir, como todo el mundo sabe, "abandonar el mundo", "salir de la existencia". Esta "venida al ser" ha de ser convenientemente traducida en términos fenomenológicos, según Henry, como un auténtico acto de "venir al aparecer", de acceso a la manifestación efectiva, habida cuenta de que toda existencia refiere en último término a un aparecer que se muestra como su fundamento. Pero este aparecer al cual viene aquello que ad-viene a la existencia no es otro que el aparecer del mundo: la luminosidad del mundo objetivo ya conocida por nosotros a través del rechazo marioniano de la primacía ontológica y fenomenológica de la "objetidad", y a la que Henry llama "verdad del mundo". En efecto, el "aparecer" en general es identificado sistemáticamente por la metafísica tradicional con el acto de manifestarse en el seno de la "verdad del mundo", con el ingresar en la mundanidad 
y su horizonte. Y en tal ingreso es en lo que consiste también, en la esfera de lo humano, el acto del nacimiento.

Sin embargo, contemplado desde la óptica de la "fenomenología de la vida", el nacimiento (el supuesto" venir al mundo") aparece, de forma paradójica, como aquello que precisamente no es posible en el mundo. Los "estados de cosas" y los objetos que los constituyen entran y salen (aparecen y desaparecen) del horizonte fenomenológico marcado por la luminosidad del mundo, sin que ello suponga acto alguno de nacimiento ni de muerte. El ad-venir al mundo no puede ser, por tanto, identificado sin más con el acontecimiento de nacer, puesto que de lo contrario hablaríamos con toda propiedad del aparecer de las cosas en la fenomenicidad del mundo como de un "nacimiento" (hecho que manifiestamente no se da). Las cosas, los objetos, vienen al mundo en ausencia de todo nacimiento, por lo que incluso, afirma Henry en C'est moi la verité: "la venida al mundo probíbe de antemano todo nacimiento concebible si es verdad que en el «fuera de sì del mundo, el abrazo de la vida consigo, estaba roto antes de producirse — si la Verdad de la Vida es irreductible a la del mundo_" (Henry 2001, p. 72). El nacimiento no es, pues, "venir al mundo", sino a la vida: el acto por el cual la vida ad-viene a sí misma y se auto-efectúa de espaldas a la "verdad del mundo". El nacimiento, puede decirse, supone una recusación de la prioridad concedida al mundo sobre la inmanencia vital subjetiva dotada de un volumen más acusado de profundidad y radicalidad que el susceptible de ser presentado por el más dogmático de los idealismos.

Pero, ¿qué quiere decir entonces realmente la expresión "venir a la vida"? Manifiestamente recalar en ella, "acceder a esa condición extraordinaria y misteriosa de ser en lo sucesivo un viviente" (Ibid.). Condición enigmática en virtud del estatus fenomenológico propio de la vida; estatuto que no consiste sino en darse con inmediatez en la pura inmanencia subjetiva, en la ipseidad patéticamente autoafectada. Al decir de Henry, precisamente la aclaración y tematización en profundidad de ese peculiar estatus ontológico específico de la vida constituye el núcleo de toda posible fenomenología del nacimiento, la cual resulta plausible únicamente en el marco más amplio de una "fenomenología general de la vida". Retengamos solamente, por el momento, el rasgo decisivo que define a tal fenomenología de la natividad, a saber: que "venir a la vida" es un acto que sólo se produce a partir de la vida misma. La vida viene de sí misma y llega a sí misma describiendo el característico bucle autorreferente propio de la auto-donación. Con ello, la vida se muestra como terminus a quo del nacimiento y no únicamente como su terminus ad quem o "punto de llegada". Así pues, si la vida es postulada como el presupuesto fundamental y originario de todo posible nacimiento, el modo fenomenológico en 
el que tal nacimiento tiene efectivamente lugar (aquel en el cual la vida engendra al viviente desde sí misma) solamente admitirá ser descrito y eventualmente aprehendido a partir del "fenómeno" de la vida auto-afectada. ${ }^{10}$

En su ensayo Phénoménologie de la naissance —incluido en el primer volumen de Phénoménologie de la vie-, Henry elabora detenidamente esta imbricación esencial entre la auto-afección patética e inmanente de la vida y la modalidad fenomenológica propia del acto del nacimiento. En primer término, el nacer comparece como un acontecimiento que contribuye decisivamente a arruinar la tradicional preeminencia de la ontología sobre la fenomenología, esto es, la prioridad de la donación del Ser sobre el aparecer de aquello que se muestra. Una manifestación originaria que precedería incluso al darse del Ser mismo y que Henry condensa en la explícita fórmula: "Autant d'apparaître, autant d'être". Advenir al ser significa, pues, como se apuntó con anterioridad, algo radicalmente distinto cuando se considera tal advenimiento en referencia a los entes mundanos y cuando es contemplado con respecto a los vivientes. El nacimiento stricto sensu — dicho propiamente al margen de todo carácter metafórico- pertenece con absoluta exclusividad al viviente. Y ello porque en caso de derivar ambos modos de venir a la existencia (el de las cosas y el de los vivientes) de la común raíz del Ser que los alumbraría y precedería en su dominio universal, resultaría preceptivo decir que la célebre roca de lava mencionada por Fichte "nace" al mismo título que lo hace un viviente humano. Se impone, pues, a fin de sortear esta posibilidad manifiestamente absurda, una transmutación radical del discurso ontológico que supone realmente su sustitución por una "fenomenología pura" capaz de "tematizar el aparecer mismo en la fenomenalidad que le es propia en cada caso" y de "reconocer y así disociar el aparecer en el que consiste el venir al ser del nacimiento del viviente, de aquel al cual todos los entes del mundo y este mundo mismo deben su ser" (Henry 2003, p. 124).

Así pues, el "Ser" al que apunta el advenimiento a la existencia implicado en el nacimiento y aquel que acompaña a la irrupción de los entes intramundanos (y del propio "mundo" en cuanto tal) en el aparecer, han de ser cuidadosamente di-

${ }^{10}$ Con todo, convendría prestar atención a este respecto a la "doble experiencia” que Grégori Jean señala a propósito de la fenomenología henryana del nacimiento: "Une telle «phénoménologie» de la naissance [...] est donc bien, dans le mouvement qui lie le vivant à la Vie qui le précède et sur laquelle il ne cesse de retarder, le lieu d' une double expérience. D'une part, elle marque l'épreuve de la quoddité du vivre [...], d'autre part, le lieu de naissance de l' illusion trascendentale de l'ego, et du recouvrement éprouvé de cette finitude en tant qu' ils se confondent avec l'ouverture de la mondanéité" (Jean 2014, p. 121). 
ferenciados y aun escindidos entre sí mediante una nítida cesura fenomenológica. Observamos en este doble pliegue de la manifestación llevado a cabo inicialmente por la fenomenología del nacimiento de Henry, la misma apertura de un horizonte de fenomenicidad alternativo al modo de aparecer del mundo que encontramos en la tematización marioniana al respecto. También en este caso la dimensión de la "objetidad" es relegada a un plano subsidiario en favor de un "elemento" de manifestación puramente "eventual" o événementiel cuya donación acontece en un dominio fenoménico paradójicamente definido por la invisibilidad. El nacimiento, al hendir y desgarrar todas las estructuras propias de la fenomenicidad ontológica (esto es, "objetiva", mundana"), no hace sino revelar el carácter inane e inconsistente que late tras la aparentemente sólida trama urdida por los fenómenos del mundo. El acto de nacer se muestra, pues, como un evento no solamente "acósmico" — en virtud de su modo de fenomenalizarse_ sino aun "anticósmico": heteróclito y radicalmente opuesto a la ahora secundaria fenomenalidad del mundo. A través del nacimiento, podríamos decir remedando a Borges en su reelaboración "estética" de las aporías de Zenón, cabría afirmar —-fenomenológicamente hablando- que, aunque nosotros soñemos de ordinario un mundo "resistente, misterioso, visible, ubicuo en el espacio y firme en el tiempo", hemos efectivamente "consentido en su arquitectura tenues y eternos intersticios de sinrazón para saber que es falso" (Borges 1986, p. 116). El nacimiento, junto con otros fenómenos paradójicos, "saturados" e "invisibles" en su donación no objetual, constituye uno de estos "intersticios" a través de los cuales el pensamiento fenomenológico nos permite arrojar una mirada ocasional a la evanescencia propia del aparecer de los fenómenos visibles mundanos. ${ }^{11}$

11 Se da aquí, dicho sea de pasada, una curiosa paradoja cuando la cuestión del nacimiento así concebida es injertada en las coordenadas del pensamiento nietzscheano al respecto. En efecto, conforme a la "psicología del desenmascaramiento" practicada por Nietzsche, el éthos decadente propio del cristianismo se expresa tanto mediante la característica desvalorización del mundo que define al ascetismo cristiano como a través del acto de "arrojar basura" sobre el acto por el cual ingresamos en ese mundo y en la vida que tiene necesariamente lugar en él, es decir, sobre el acto sexual que da lugar precisamente al nacimiento. Pero he aquí que, desde el punto de vista fenomenológico que nos hallamos considerando, es justamente uno de esos dos factores - el nacimiento que constituye nuestro origen- el instrumento que contribuye de modo determinante a desvalorizar (no ya religiosa, sino fenomenológicamente) el segundo, esto es, a mostrar la inanidad ontológica del mundo y la subsidiariedad de todo aquello que se muestra en su horizonte fenomenológico. Merecería la pena elucidar con más detenimiento esta paradoja. 
Es, asimismo, esta endeblez propia del aparecer del mundo la que muestra el auténtico sentido del nacimiento: no el de "venir al mundo" o "al Ser", sino el de "acceder a la vida de tal forma que uno mismo devenga viviente, tomando parte desde entonces en la experiencia infrangible del vivir, en su sufrimiento y en su disfrute" (Henry 2003, p. 128). "Nacer" significa fundamentalmente, por tanto, el evento merced al cual la vida "s'accomplit", es decir, accede a su efectivo cumplimiento en cuanto tal de modo puramente inmanente. ${ }^{12}$ A esto se debe precisamente el que ningún acceso o advenimiento a la condición de viviente, al vivir propio de la vida, resulte posible ni pensable en el horizonte objetivo marcado por el modo de fenomenicidad del mundo. Tal es la estructura en cierto modo circular que preside la relación entre mundo y nacimiento propio. Además, resulta preceptivo reparar en el hecho de que este advenimiento a la vida del que venimos de hablar jamás acontece como resultado de una previa decisión de carácter voluntario, dado que de forma palmaria ningún sujeto viviente se encuentra en condiciones de resolverse libremente a nacer, a acceder al cumplimiento de la vida, puesto que en el hipotético momento de tomar tal decisión (aún) no se da siquiera como tal viviente. Aquí reside, según reconoce Henry, un característico rasgo constitutivo del enigma del nacimiento: "que el nacimiento es una especie de comienzo absoluto y que este comienzo absoluto presupone, sin embargo, un «antes de él». Es esta antecedencia al comienzo absoluto del nacimiento por parte de un «antes de él» más absoluto que él, la que hace del fenómeno del nacimiento una experiencia límite, remitiendo en la propia experiencia que ella hace de sí a aquello que parece imposible de experimentar" (Henry 2003, p. 130). Se trata, por tanto, de elucidar la significación propia de esta imposibilidad de establecer mención alguna con respecto al origen implícitamente contenida en todo acto de nacimiento.

Desde la perspectiva fenomenológica radical adoptada por Henry, el sentido de la imposibilidad de decidir con carácter previo acerca del nacer o no nacer ha de ser desvinculada de todo contexto voluntarista o "volitivo". No se trata, pues, de "querer" o "no querer" acceder a la existencia, de ad-venir a la condición de viviente de modo libremente voluntario o de cualquier otro, sino de venir a la

12 Desde la perspectiva adoptada por Henry, el que la vida "se cumpla" significa fundamentalmente y antes que nada "Qu'elle s'auto-affecte, que la matière phénoménologique de cette affection originelle est un pathos, que cette auto-affection pathétique est un procès, l'éternel procès en lequel la vie parvient et ne cesse de parvenir en soi — de telle façon qu'il n'est aucun autre moyen de parvenir à la vie et dans son vivre qu'à l'intérieur de ce procès d'auto-affection et par lui” (Henry 2003, p. 129). 
existencia de un modo totalmente independiente de la apertura original a la exterioridad de un mundo postulada como inevitable por la noción heideggeriana de "ser-en-el-mundo". En efecto, en cuanto ente puesto en franquía por su constitutiva Erschlossenheit, el Dasein heideggeriano se define esencialmente por su In-derWelt-sein, por su necesaria remisión al "afuera" representado por el horizonte de lo mundano. Es necesario, al decir de Henry, invertir absolutamente los términos de la cuestión. Solamente en y a través de la vida podemos nosotros acceder al Dasein de un modo radicalmente ajeno a la fenomenicidad "objetual" propia del mundo. Así, de forma inversa a la postulada por Heidegger, no es sólo que no nos sea dado el acceso a la vida únicamente en y por el Dasein, sino que realmente sucede lo contrario: solamente en y a través de la vida nos es por esencia accesible el Dasein. Contemplada desde la perspectiva de una fenomenología del nacimiento, esta inversión que convierte al Dasein en "Dasein viviente" abre una modalidad de manifestación y fenomenalización radicalmente distinta a la del aparecer del Dasein. Desde el momento en que se acepta la tesis conforme a la cual únicamente en la vida se ad-viene al Dasein, la cuestión del nacimiento resulta profundamente dislocada en la medida en que se ve compelida a renunciar a toda referencia al mundo y al "ser-en-el-mundo": a abandonar todo rasgo siquiera mínimamente relacionado con ellos ("existenciarios" y "categorías" incluidos). Ninguna estructura "existencial" interesa ahora verdaderamente a la fenomenología del nacimiento, para la cual deviene única cuestión genuinamente pregnante aquella orientada a desvelar el modo en el cual se viene, en general, a la vida.

La pregunta por la forma en la cual el viviente accede a la vida, es decir, la cuestión fenomenológica del nacimiento, apunta, cuando es captada de forma originaria, a un nacimiento igualmente originario. Henry llama "nacimiento originario" (Ur-naissance) a este evento primigenio que se hurta por igual a la mirada científica (biológica, singularmente), a las categorías propias del pensamiento filosófico tradicional y a la consideración ingenuamente banal con la que el individuo común observa el fenómeno del nacimiento. En la Ur-naissance se cumple el nacimiento de la ipseidad trascendental en el seno de la absoluta inmanencia propia de la vida, de tal modo que tal nacimiento acontece al margen del mundo y de espaldas a todo "ser-en-el-mundo". De este modo, venir a la vida por parte del viviente significa ad-venir de ella y en ella, con lo que, a su vez, esa misma vida se muestra como inicio y punto de partida del nacimiento (de ese "ad-viento" a sí en el que la vida consiste), no como su meta o punto de llegada. Así pues, dado que todo Ur-naissance remite de modo originario a "la esencia previa de la vida" y se nutre de ella, el sujeto viviente, esto es, aquel no empírico o meramente "óntico" 
(al que Henry llama "hombre original”), no puede ser definido a partir de sí mismo de forma exclusiva. Es necesario captarlo siempre desde el prisma de la vida que antecede al ego viviente de manera radical y eterna "en el proceso mismo por el cual ella no deja de engendrarlo como aquello que resulta necesariamente, por lo cual ella no deja de darle nacimiento" (Henry 2003, p.132). La vida genera, pues, al ego viviente (le "da a luz", podría decirse) al engendrarse a sí misma y de modo simultáneo a su proceso de auto-afección. La vida, merced a tal "proceso", accede a sí misma, se experimenta a sí misma en el sufrirse y en el gozar de sí que constituyen su más profunda esencia, y al hacerlo, en virtud de este auto-movimiento por el que la vida absoluta ad-viene a sí, "da a luz" a ese sí-mismo individual y singular que es el ego de cada cual. Esta generación coincide, por tanto, al decir de Henry, con "mi nacimiento trascendental" (Id.133).

¿Resulta, pues, correcto y pertinente afirmar que yo —en tanto que ego individual y determinado- "he nacido"? Manteniendo a la vista los postulados fenomenológicos asentados por Henry, habría que aclarar que, propiamente hablando, cada sujeto particular ha nacido en la medida en que ha sido engendrado como ego o soi-même individual en su respectivo Ur-naissance trascendental. Pero, tal Urnaissance o "proto-generación" originaria constituye realmente una modalidad particular del proceso eterno mediante el cual la vida absoluta se origina a sí misma. ${ }^{13}$ Dado que la vida absoluta es por esencia ingénita, carente de todo nacimiento, puede legítimamente postularse que el sujeto partícipe en ella mediante su Urnaissance particular "no ha nacido" en cierto modo, puesto que secunda de alguna forma el carácter paradójicamente eterno inherente al proceso de auto-afección que define a la vida. En el pathos de su permanente auto-afección, la vida se experimenta a sí misma en términos de esta ipseidad individual que se encuentra en el fundamento de todo ego singular y que todo yo determinado presupone como su auténtica condición de posibilidad. Es de este modo como, según Henry, tiene verdaderamente lugar el nacimiento del ego trascendental: en el ámbito replegado y "nocturno" de la absoluta inmanencia.

El nacimiento del ego individual en la vida universal absoluta sitúa a la fenomenología del nacimiento ante una cuestión en cierto modo inversa a aquella que

13 Como indica pertinentemente Jean Reaidy: "Nous ne pouvons pas exister hors de notre naissance dans la vie, hors de cette passion que se vit comme rapport fondamental à soi dans la vie absolue. La pratique phénoménologique relative à une phénoménologie de la naissance est avant tout une pratique d'accueil de tout ce qui se manifeste dans ses excès dans la simplicité du rapport charnel pluriel et sa phénoménalité trascendentale” (Reaidy 2009, p. 14). 
venimos de elucidar, a saber: desentrañar el modo en el cual se revela y se da a cada ego viviente aquello que posibilita su auto-donación y que, por tanto, ha de precederlo radicalmente. En último término, se trata, pues, de la cuestión relativa al tipo peculiar de relación que es posible distinguir entre aquello que ha nacido y aquello que carece de nacimiento por esencia y en sentido absoluto. Dicho de otro modo: sería necesario clarificar la forma en la que el viviente concreto y singular establece, en su acto de Ur-naissance trascendental, un fundamental vínculo con ese proceso de auto-producción de la vida absoluta del cual jamás puede decirse que haya nacido, sino que se muestra esencialmente sin nacimiento. Esta ligazón entre lo nacido y lo no nacido no puede, según la descripción de Henry, sino desembocar en una situación abiertamente paradójica. En efecto, por un lado, es necesario postular una radical antecedencia de la vida absoluta y su proceso de auto-generación con respecto a la génesis de todo ego particular, dado que aquélla ha de ser contemplada como el presupuesto necesario de ésta en la medida en que cada ipseidad singular es engendrada por mor de tal auto-generación. Desde el punto de vista del viviente individual, la vida absoluta constituye, por tanto, aquello que Henry llama "un antes absoluto"; un pretérito que se auto-produce con absoluta antelación y en ausencia del cual jamás le sería concedido a tal viviente singular el efectivo acceso a la vida. Pero, por otro lado, este supuesto previo de todo ego trascendental se muestra simultáneamente como su condición: la auto-donación inmanente de la vida absoluta que se actualiza y repite, en cierto modo, en la auto-afección concreta e individual de cada ego, y a través de la cual ella es, a su vez, paradójicamente engendrada.

El ego se nutre constantemente, por tanto, de su ligazón al auto-cumplimiento de la vida absoluta, generando así un circuito de referencia con respecto a éste privado del cual — siquiera durante un único instante- desaparecería de inmediato. De este modo, el acontecimiento representado por el ad-venir a la vida absoluta y a su auto-generación por parte del ego particular, se aleja definitivamente de toda hipotética tentativa orientada a parangonarlo en algún aspecto con aquello que ordinariamente se designa como "acto de nacimiento". El sujeto viviente, lejos de presentarse como un ser que nace en un momento determinado temporalmente localizable y susceptible de ser señalado, nace en cierto sentido perpetuamente, al ser engendrado de modo diacrónico por el curso de la eterna autogeneración de la vida absoluta. Es en este sentido en el que cabe entender la prima facie sorprendente afirmación de Henry conforme a la cual "el nacimiento no es un evento, sino una condición” (Henry 2003, p. 139).

Esa condición que es la nuestra en tanto que seres vivientes, nos convierte en "hijos trascendentales de la vida absoluta"; nos desvela no como descendientes 
de individuos meramente "empíricos", sino como seres cuya genuina filiación ha de buscarse en el modo en el que esa vida se genera a sí misma. El ego viviente no nace, por tanto, de forma biográficamente sincrónica (a una hora concreta de una fecha determinada), sino que la efeméride de su nacimiento se celebra cada minuto, cada fracción de segundo en la cual participa del flujo inmarcesible de la vida y éste se manifiesta en él, es decir, mientras retiene su condición de viviente. Mientras no se da la muerte — podría decirse- hay siempre nacimiento. Nacimiento perenne. Es debido a ello que — como atestigua cumplidamente todo lo apuntado con anterioridad - Henry se siente legitimado para afirmar, al final de su periplo reflexivo en torno a la cuestión de la natividad, que "La vida del ego trascendental es la fenomenología de su nacimiento" (Henry 2003, p. 142).

Como hemos tenido ocasión de observar, el acontecimiento trascendental de la natividad del ego tampoco acontece en la fenomenología henryana (como sucedía asimismo en la fenomenología del don de Marion) en el ámbito del aparecer propio de los "fenómenos del tipo objeto". El nacimiento constituye también aquí un singular tipo de fenómeno cuya fenomenicidad misma acontece y se cumple en una esfera fenomenológica extraña a la del horizonte del mundo en cuyo seno eclosionan de ordinario los "fenómenos corrientes", "de derecho común” y "del tipo objeto". El nacimiento no es ciertamente un "objeto", una cosa, pero, aun perteneciendo al reino ontológico de los "acontecimientos", comparece a su vez en términos de "acontecimiento" sumamente particular. Investido de rasgos distintivos que lo singularizan en tanto que fenómeno absolutamente "acontecial" (Marion) a la vez que radicalmente inmanente (Henry). El crucial aspecto común a ambas caracterizaciones radica — como apuntábamos al comienzo — en su compartida distancia con respecto al modo de fenomenicidad propio del mundo objetivo, en su minusvaloración de la modalidad objetual que asumen los elementos que lo pueblan a la hora de aparecer y mostrarse en la fenomenicidad que les es propia. Así pues, parece que cuanto más en serio se toma, fenomenológicamente hablando, el singular "fenómeno" del nacimiento, mayor es nuestro volumen de disposición a considerar los fenómenos corrientes mundanos como incidentales y accesorios a favor de un tipo de fenomenicidad que, si bien no es la del mundo, reviste acaso para nosotros mayor grado de envergadura y significación que ésta. Esta escisión del fenómeno del nacimiento con respecto al aparecer mundano se halla preñada de implicaciones y consecuencias relativas no solamente a la concepción de la fenomenología como "disciplina filosófica", sino al modo de considerar nuestra relación con el mundo de lo dado a nuestra percepción en general. Únicamente podemos aquí esbozar, de modo conclusivo, algunas de ellas. 


\section{CONCLUSIÓN: UN ACONTECIMIENTO SIN HUELLA DE “OBJETIDAD”}

En primer lugar, el peculiar estatus ontológico y gnoseológico que, siguiendo a Marion y Henry, acabamos de reconocer al fenómeno del nacimiento, modifica radicalmente el sentido propio de la noción fenomenológica clave de "intencionalidad" tal y como fue teorizada originalmente por Husserl y aplicada con posterioridad por sus epígonos. En efecto, la máxima peculiaridad propia del fenómeno del nacimiento radica acaso en el hecho paradójico de que se trata de un "fenómeno" del cual tenemos a la vez absoluta constancia y nula conciencia. Constituye tal vez el único fenómeno acerca del cual podemos disponer de un inequívoco y vasto volumen de certeza sin tener de él noticia intuitiva alguna. Y esto significa, en contexto fenomenológico, sin que tal fenómeno se muestre —al aparecer- como correlato "objetivo" de la intencionalidad constitutiva de toda conciencia. El nacimiento, ciertamente, no aparece en ningún momento como nóema de nóesis alguna. En este sentido, admite legítimamente ser designado como un fenómeno no-intencional, "a-intencional" y extraño, por tanto, a la intuición. Un "fenómeno" que jamás se presenta en términos de "objeto" o "evento" dado a la representación por parte de un sujeto percipiente, pero que, sin embargo, constituye algo de cuyo carácter efectivamente acontecido no le es posible dudar a tal sujeto, dado que ha de presuponerlo necesariamente en tanto que raíz originaria de su propia condición actual en tanto que existente tout court. De este paradójico modo, un fenómeno "acontecial" que por esencia jamás me fue ni me será dado, puesto que no es un objeto y sólo acaece "contra-intencionalmente", ${ }^{14}$ constituye la mayor y más inquebrantable de mis certezas. En este sentido, el nacimiento cumple, en contexto fenomenológico, una función análoga a la desempeñada por la certeza absoluta del cogito en cuanto fundamentum inconcussum veritatis en el marco de la metafísica cartesiana, si bien de un modo mucho más ontológicamente evanescente y epistemológicamente problemático.

Así pues, siempre nos resulta posible orientar intencionalmente la conciencia hacia el evento del nacimiento ajeno (el de los propios hijos, por ejemplo), pero curiosamente nos está vedado de forma irremediable el acceso al fenómeno de nuestro propio nacimiento. Y ello no (sólo) debido a nuestra imposibilidad para presenciarlo de modo consciente por razones estrictamente biológicas, sino sobre

\footnotetext{
14 Sobre esto, apunta Marion: "si la contre-intentionnalité qui m'advient précède l'intentionnalité que je déploie, si donc le non-encore-objet donné précède l'objet, ne devrait-on pas en conclure que l'événement se manifeste avant l'objet et que l'objet n'apparait jamais que comme un donné restreint, un événement qui s'oublie?" (Marion 2015, p. 26).
} 
todo porque el nacimiento constituye la más intensa de todas las posibles quiebras de la memoria. No hay memoria posible del nacimiento. Éste, en su retracción temporal imposible de revertir, se erige como la mayor penuria de la anámnèsis, como el acontecimiento vitalmente más decisivo y a la vez más irrecuperable mediante la rememoración. El nacimiento pertenece ciertamente, en este sentido, a una temporalidad que no es ya la de la existencia consciente, sino que se sitúa en un pasado que jamás ha sido presente para el sujeto. Un profond jadis, jadis jamais assez (Valéry) análogo a ese "tiempo inmemorial" externo al tiempo mundano en cuyo seno tiene lugar, según Levinas, la involuntaria asignación y adquisición de la responsabilidad ética hacia el Otro y su indigencia por parte del sujeto individual.

El nacimiento carece así, fenomenológicamente hablando, de "mención", de esa Meinung husserliana que permitiría hipotéticamente declararlo de forma originaria, puesto que introduce una esencial dilación, una constitutiva moratoria en el evento mismo de nuestro origen que nos alienará en lo sucesivo con respecto a él de modo irreparable. Es en este sentido en el que Claude Romano habla oportunamente de una "originaria no-originalidad del origen", esto es, del hecho de que nacer implique ser uno mismo, ser libre, comprender el sentido de la propia vida o posibilitar la proyección de posibilidades, pero todo ello siempre de modo originario y nunca de forma original. Originaria pero no originalmente. Aquí muestra acaso su más crucial y profunda significación ese hiato que escinde el "fenómeno" del propio nacimiento y nuestra posible conciencia o rememoración de él al cual acabamos de referirnos. Tal distancia ha de ser interpretada, pues, en términos de cesura originaria que habrá de determinar la totalidad del subsiguiente periplo vital individual resultante de ese origen fragmentado y transido de desasosiego. En palabras de Romano: "Ese desfase originario de lo original y lo originario es lo que determina el sentido contecedero primero del nacimiento" (Romano, p. 109).

Por otro lado, es posible inquirir acerca del papel asumido por el nacimiento en el marco del dominio acotado por el "principio de todos los principios" husserliano. En su formulación original en el parágrafo 24 de Ideen I, tal principio reza como sigue: "toda intuición en que se da algo originariamente es un fundamento de derecho del conocimiento; todo lo que se nos brinda originariamente [...] en la «intuición», hay que tomarlo simplemente como se da, pero también sólo dentro de los límites en que se da" (Husserl, p. 58). Pues bien, ¿Qué rol asume — si es que le es dado adoptar alguno- la intuición entendida como "fundamento de derecho del conocimiento" en el caso de la captación del fenómeno del nacimiento? ¿Qué es lo que "se da" y dentro de qué límites "se da" la donación propia de la natividad en tanto que fenómeno "acontecial"? ¿Puede realmente decirse que el fenómeno del nacimiento "se da" de algún modo? 
Sin duda, puesto que - como asientan los postulados fenomenológicos acerca del don- todo aquello que se muestra ha de "darse" con carácter previo. Y el nacimiento ciertamente "se da", aunque no se dé a su protagonista de modo efectivo y sí siempre a los otros, a los demás, a quienes les es concedido el presenciarlo intuitivamente de manera directa. Así pues, la intuición (propia) resulta despojada, en el caso del fenómeno del nacimiento (propio), de la investidura de basamento de derecho cognoscitivo, habida cuenta de que aquello que habría de "darse" a ella lo hace de un modo y dentro de unos límites que exceden palmariamente el posible dominio en cuyo interior le es brindada a la intuición la posibilidad misma de desplegarse.

Todo lo anterior apunta al hecho de que el fenómeno del nacimiento —en tanto que fenómeno que propiamente "no es", pero que, no obstante, "se da"pertenece a la categoría de aquellos fenómenos no comunes ni corrientes que comparecen paradójicamente ante la mirada como no-objetos y, por tanto, como "fenómenos invisibles". Fenómenos que, sin mostrarse (pero dándose) ni tornarse visibles en la apertura de la fenomenicidad del mundo objetivo, ejercen, sin embargo, una profunda influencia efectiva sobre nosotros en tanto que sujetos vivientes y cognoscentes. En efecto, ¿qué fenómeno (a pesar de su carácter irrememorable, no intuitivo, invisible y "acontecial") es susceptible de ocasionar un mayor volumen de influencia sobre el sujeto viviente que el nacimiento, en cuanto éste se presenta como el presupuesto originario de todo el resto de los fenómenos posibles que tal sujeto pueda hipotéticamente encarar a lo largo de aquella misma existencia de la que el nacimiento es origen? En este sentido, el nacimiento ha de ser incardinado (junto a elementos tales como la imagen pictórica, el rostro ajeno o la auto-afección patética de la vida que acontece en la pura inmanencia subjetiva) en la esfera de aquellos fenómenos no-objetuales cuya fenomenicidad se despliega de tal forma que su exuberancia intuitiva colma y ciega la mirada común. Fenómenos que Marion identificaría como "saturados" ("paradojas") y Henry como "invisibles", y que, en todo caso, responden a la observación del primero según la cual "La saturación de ciertos fenómenos debe entenderse como la consecuencia formal de su fenomenalidad a la medida de la donación” (Marion 2016, p. 185).

La tarea propia de la fenomenología (y aun de la filosofía tout court) residiría, pues, secundando la ya aludida exhortación tardía heideggeriana a la práctica de una Phänomenologie des Unsichtbaren ("fenomenología de lo inaparente"), en tornar en cierto modo visibles — si no a la mirada, sí al menos al concepto- aquellos fenómenos cuyo modo de donación los sustrae de principio a toda facultad de visibilización posible. ¿Por qué resulta tan decisivo, pues, el evento de la natividad? A este respecto, porque el fenómeno del nacimiento, en tanto que fenómeno 
originario e inexperimentable por excelencia, admite ser acaso interpretado como una silenciosa admonición. Un tácito signo que apunta, a modo de pista e indicio, hacia el desvelamiento de uno de los más palmarios y a la vez larvados hechos que presiden nuestro periplo vital en el mundo. El hecho de que las instancias cruciales que verdaderamente determinan nuestra condición, que realmente nos interesan en cuanto seres vivientes, acontecen más acá de la memoria, más allá de la percepción, al margen del estatus concreto de "objetos" o "cosas" del mundo: en el dominio simultáneamente tenue y primordial de la invisibilidad.

\section{Jaime Llorente Cardo IES Campo de Calatrava (Ciudad Real) jakobweinendes@gmail.com}

\section{BIBLIOGRAFÍA}

Borges, J. L. (1986), Discusión, Madrid: Alianza.

Henry, M. (2001): Yo soy la verdad, Salamanca: Sígueme.

HENRY, M. (2015): La esencia de la manifestación, Salamanca: Sígueme.

Henry, M. (2003): Phénoménologie de la vie I. De la phénoménologie, Paris: PUF.

HUSSERL, E. (1985): Ideas relativas a una fenomenologia pura y una filosofia fenomenológica, México: FCE.

JEAN, G. (2014): "Michel Henry et la métaphysique de la présence", en G. Jean y J. Leclercq (ed.), Lectures de Michel Henry. Enjeux et perspectives, Lovaina: Presses universitaires de Louvain, pp. 99-121.

LEVINAS, E. (1987): De otro modo que ser, o más allá de la esencia, Salamanca: Sígueme.

MARION, J.-L. (2016): Reprise du donné, Paris: PUF.

MARION, J.-L. (2010a): De surcroît, Paris, PUF.

MARION, J.-L. (2010b): Certitudes negatives, Paris: Grasset.

Marion, J.-L. (2015): Figures de phénoménologie: Husserl, Heidegger, Levinas, Henry, Derrida, Paris: Vrin.

PATOČKA, J. (1995): Papiers phénoménologiques, Grenoble: Jérôme Millon.

PATOČKA, J. (2016): Le monde natural comme problème philosophique, Paris: Vrin.

Ricoeur, P. (2009): Philosophie de la volonté 1. Le Volontaire et l'Involontaire, Paris: Points.

REAIDY, J. (2009): Michel Henry la passion de naître: Méditations phénoménologiques sur la naissance, Paris: L'Harmattan.

Romano, C. (2012): El acontecimiento y el mundo, Salamanca: Sígueme.

SCHELLING, F.W.J. (1989): Investigaciones filosóficas sobre la esencia de la libertad bumana y los objetos con ella relacionados, Barcelona: Anthropos. 